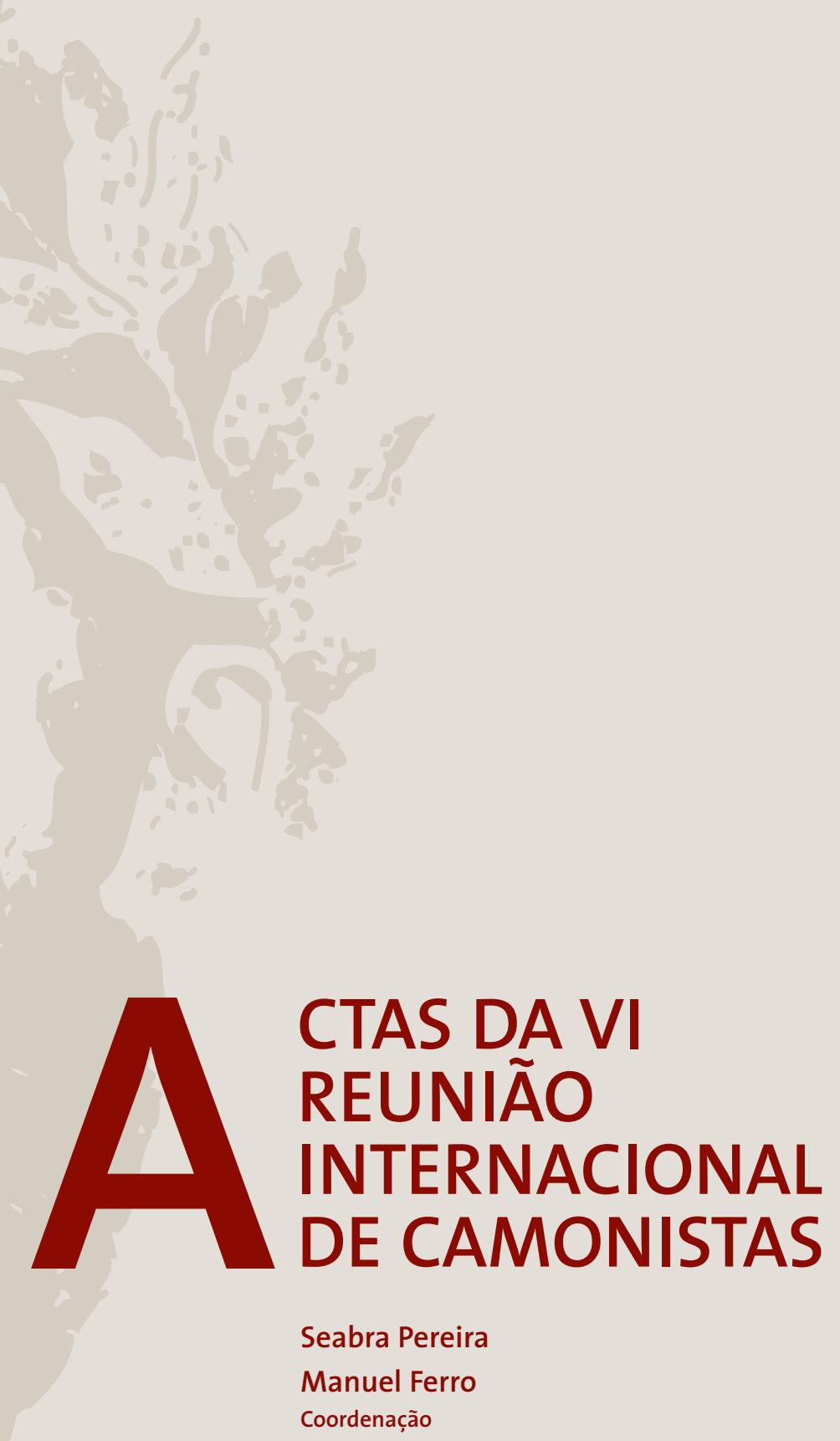


Francisco Maciel Silveira

Universidade de São Paulo (USP)

QUE FAREI COM ESTE LIVRO? - DE OS LUSÍADAS, SEGUNDO SARAMAGO

\section{Ler a dois olhos.}

Leiamos a peça Que farei com este livro? (1980) do Sr. José Saramago a dois olhos. Para tanto, distingo um olho do outro.

Com o olho direito, ler-se-á segundo a visão do leitor inexperto. Com o esquerdo, ler-se-á segundo a óptica de um leitor experto - um camonólogo aquilino, digamos.

Não se pense que estou aqui a inventar um novo modo de ler. Antes, entro no jogo proposto pelo Sr. José Saramago.

Em cena fulcral da peça, primeiro quadro do segundo ato (pp. 105-106), a personagem Damião de Góis, a propósito da trama que empece a publicação de $O s$ Lusíadas, não nos ensina que há pelo menos duas maneiras de ler e que "a diferença [interpretativa e judicativa da leitura] estará nos olhos que o lerem»?

Portanto, via Damiáo de Góis, propóe o Sr. José Saramago o mote para ler seu texto, humberto-ecoando que a obra, depois de aberta, admite distinta leitura, interpretaçáo e valoração, conforme os olhos que o lerem. Aqui, no caso dessa glosa e escólio, dois: um direito - o do leitor inexperto - e um esquerdo - experto, aquilino.

\section{Sob o olho direito do leitor inexperto.}

Tracemos o perfil do leitor inexperto. Tem suas luzes e brilho, tendo ou não lustrado os bancos acadêmicos. Gosta evidentemente de ler e o faz para dis-trair-se, na acepção ortega-y-gassetiana do termo, isto é, "para evadir-se, escapar, trazer-se a si mesmo deste mundo em que vive para outro irreal", onde descansa da planura de sua vidinha, mas onde também vive uma vida vicária, enriquecendo-se com experiências que talvez nunca tivesse a oportunidade de experimentar (José Ortega Y Gasset, $A$ idéia do teatro, SP, Perspectiva, 1978, p 51).

Por uma dessas casualidades próprias da ficção, nosso leitor inexperto - em verdade leitora, Manua chamada - está a ler Que farei com este livro? Que nos conta sua visão privilegiada, embora inexperta?

Que a ação da peça, a transcorrer em Almeirim e Lisboa entre Abril de 1570 e Março de 1572, é a composição e publicação de Os Lusíadas. 
Não lhe ocorre perguntar se a índole do assunto é absolutamente nova, se o seu autor, «sem exemplar a que se arrimasse nem norte que seguisse», também "navegava por mares nunca dantes navegados", a exemplo do poema Camóes, de Almeida Garrett. E não lhe ocorre perguntar porque nunca leu os dez cantos nem o prefácio do cometimento garrettiano.

E ademais, se os tivesse lido, poema e prefácio, seus olhos não haveriam de confundir alhos com bugalhos, porquanto, apesar de o assunto e motivo serem idênticos, Que farei com este livro? retrata outro Camões, antítese da garrettiana estátua tribunícia que, em Sintra, recita os 8.816 versos de sua epopéia para os ouvidos moucos mas benevolentes de D. Sebastião. Fora nossa leitora inexperta versada em kristeviana e linda-hutchoniana intertextualidades, diria que o Sr. José Saramago entoou, etimologicamente, uma paraode, um canto paralelo e contra os dez cantos de Almeida Leitão Garrett.

As personagens da peça, deduzirá Manua, encarnam a falta de rumo, perplexidade e apatia da Nação.

À volta do rei, D. Sebastião, gravita uma nobreza enfatuada e desvirilizada, um clero cúpido e hipócrita, portanto, personagens menores, meros figurantes, quase todos despersonalizados, como o $1^{\circ}, 2^{\circ}, 3^{\circ}, 4^{\circ}$ Fidalgos, o Frade.

Na luta que se trava pelo poder, a cavaleiro da situação, - justo termo pois de Ácteon em montarias cinegéticas e de cavalarias em África se tratava -, primam os irmãos Gonçalves da Câmara, quão privados de el-rei já denuncia o sobrenome, um Luís, confessor de D. Sebastião, outro Martim, secretário de Estado, além de outras puridades e presidências e desembargos do Paço.

Como nos compêndios de história que foi obrigada a consultar no Liceu, ambos os jesuítas são, na peça, culpados pelas suspeitas misoginia e misogamia de D. Sebastião.

Em 1572-1573 era enorme o descontentamento com os desvarios privados do Rei e o despotismo público dos Câmaras, descalabros que inspiravam pasquins anônimos, como o que se lê da boca do Pe. Luís da Câmara em diálogo com o irmão Martim no primeiro quadro do primeiro ato:

“ (Lê) El-rei nosso senhor, por fazer mercê a Luís Gonçalves e a Martim Gonçalves, e aos padres da Companhia, há por bem de não casar estes quatro anos, e de estar com eles abarregado. (Martim da Câmara ri).”

E com ele na ocasiâo também riu nossa leitora inexperta e rir-se-ia mais ainda, agora de íntima satisfação, se não ignorasse que o Sr. José Saramago, apoiado em fontes históricas, dramatizou, no referido quadro e ato, informaçáo que assim se lê em Vida ignorada de Camóes, do Sr. Hermano Saraiva (Lisboa, Publicaçóes Europa-América, primeira edição de 1978 , cito pela segunda, de 1980, pp. 382-383):

"Alguns pasquins que circularam por essa altura dão a medida do descontentamento reinante. Ninguém ousava falar abertamente, porque as críticas acabavam no desterro e na cadeia, mas circulavam papéis anônimos em que os Câmaras eram responsabilizados por não deixarem casar o rei, para o terem mais dependente, e onde se chegava a dizer que estavam amancebados com o jovem monarca" (Cf. Que farei com este livro?, primeiro quadro do primeiro ato). 
Partidos opostos, inimigos até, pois um autonomista e outra defensora de supeitosa união ibérica, mas os dois em busca de aliança que pusesse freio à influência e poder dos Câmaras - o tio e a avó de el-rei, o Cardeal D. Henrique e D. Catarina de Áustria, ambos preocupados com o desgoverno e o nebuloso rumo do Reino.

"Isso é o que passa no Paço», pensa Manua, nossa leitora inexperta, feliz por regurgitar frase na feição e estilo do Autor. Ressoante de fontes nossa memória?, uma informação, uma frase vêm à tona, - de que profundas leituras não o sabemos? -, mas já que vieram à tona cumpre salvá-las, repeti-las, «isso é o que passa no paço» (e prosseguir na mesma toada a glosa), "freqüentação também de personagens com mais passos», como os viajados Damiáo de Góis, Diogo do Couto e Camóes, esses dois matalotes recém-chegados à Pátria «metida no gosto da cobiça e na rudeza duma austera, apagada e vil tristezd».

São 8:00 hs. no despertador de nossa leitora inexperta, quando, em Fevereiro de 1571, ali mesmo no bairro do Castelo, em casa de Damiáo de Góis, localizada no primeiro quadro do segundo ato, transcorre a cena axial da peça.

Basta contar os quadros que a compóem, o primeiro ato com sete, o segundo com oito, essa cena, portanto, bem no meio da peça, a dividi-la, tordesilhas de revelação e consciência: trata-se da apagada e vil tristeza do presente a empanar a memória gloriosa da heroicidade pretérita. Ali estão reunidos Diogo do Couto, Camóes e obviamente o dono da casa, o Sr. Damião de Góis.

Apressada pelo relógio, meu Deus são já 8:15 hs., divertida em outra realidade perdera a noção do tempo nossa leitora inexperta, e agora precisa deixar a cena em que se vê metida, fazer suas abluçôes matinais, tomar café correndo e correndo tomar o autocarro rumo ao trabalho.

“- Com licença, Srs. do Couto, Camões e Góis, mas estou atrasadinha, fiquem à vontade, a quitinete ao dispor de vossas mercês, na geladeira há sardinhas cozidas e carapaus frescos, façam bom proveito, adeusinho, até amanhã."

\section{Sob o olho esquerdo do leitor aquilino.}

Exatamente onde Manua deixou seus olhos, primeiro quadro do segundo ato, tem os seus pousados, negros como sotaina, a Dra. Legenda Vaz Est, nossa leitora experta.

No rigor de togas e capelos, não é camonóloga a Doutora, mas tem um olho - aqui esquerdo - aquilino, inquisitorial. Tanto que suas notas de leitura, deita-as num canhenho que intitula Manual de inquisiçôes literárias e no qual se lêem as seguintes observaçóes:

I. Peça: Que farei com este livro?, do Sr. José Saramago, 1a ed. de 1980. Compulso a 2a ed., com prefácio de Luiz Francisco Rebello, Lisboa, Editorial Caminho, 1988.

II. Nodal o primeiro quadro do segundo ato. Aí estão reunidos Diogo do Couto, Camôes, Damião de Góis.

III. Nesse ponto começa a releitura saramaguiana de Os Lusíadas, via outras leituras. Em Lisboa, Camốes teria acrescentado ao texto primitivo de seu poema estâncias e versos inspirados pela apagada e vil tristeza do presente (pp. 103-104): 
"Damião de Góis: - Quando chegastes da Índia, era o vosso livro como hoje é? Não precisais responder. Tive aqui em minha casa o manuscrito, li-o com grande cuidado e atenção, mas de tanto náo precisaria para distinguir, nas diferenças de tinta, os acrescentamentos escritos estando vós já em Portugal e por causa do que cá viestes encontrar.

Camóes: - Assim é. Lembrai-vos que de el-rei eu não sabia mais do que existir. Em Lisboa é que escrevi a dedicatória...

Damiāo de Góis: - Que mais?

Camóes: - O final do canto V, também do sétimo, algumas oitavas do canto nono, outras no canto décimo...

Damião de Góis: - E, se bem te conheço, ainda escreverás, se não foi escrito já, o bastante para amanhã se saber que os parentes de Vasco da Gama não cuidaram de honrar, como deviam, o fundador da casa da Vidigueira.

Camôes: - Escrito está, não duvides.

Damião de Góis: - O que trouxestes da Índia, Luís Vaz, foi a história do antigo Portugal, mais a grande navegação. Tudo isso que acrescentastes são casos dos nossos dias de agora, deste tempo em que não sabemos para onde Portugal vai”.

No referido primeiro quadro do segundo ato, depreende-se do diálogo travado entre Damiáo de Góis e Camóes que o poeta teria acrescentado em Lisboa:

a) a dedicatória, estâncias 6 a 18 no canto I;

b) o final do canto V, ou seja, as estâncias 92 a 100, aguilhoado pela recusa do neto de Vasco da Gama em patrocinar a imprimissão do livro;

c) o final do canto VII, isto é, as estâncias 78 a 87, acerca dos infortúnios que o perseguem ( VII, 78-82) e do intuito de náo empregar seu canto "em quem o náo mereça" (VII, 83-87);

d) as "algumas oitavas do canto nono", pela contemporaneidade do conteúdo, são as estâncias 26 a 29 (= as cavalarias cinegéticas do Acteon Sebastiáo) e o epifonema, estâncias 92-95, contra o ócio ignavo, a cobiça, a ambição, a prepotência;

e) as "outras" oitavas acrescidas no canto décimo são as estâncias 145-156 do epílogo (estrofes em que aconselha o soberano e propóe-se a cantar a aventura marroquina) e possivelmente a estância 119 (crítica aos jesuítas).

IV. Nesse capítulo de aditamentos posteriores ao poema, menos que uma releitura direta de Os Lusíadas, a óptica do Sr. José Saramago vê pelos olhos de bibliografia dedicada a Camóes. A tese dos acrescentamentos feitos em Lisboa é plausível, seja pelo soar parentético das estâncias, seja por constituirem epifonemas, contudo a idéia fora já defendida por:

a) Aquilino Ribeiro - Luis de Camóes. Fabuloso. Verdadeiro, Lisboa, Bertrand, 1974, vol II, p. 148 - onde se lê referência à inserção se não de todo o epílogo pelo menos das três estrofes finais (154-156):

"o que nos induz a supor que o poeta não dera ainda a obra por conclusa, propondo-se acrescentá-la aqui e além, e retocá-la (...) ou que a vesânia heróica, que grassava nas altas esferas do poder o contagiasse - e certos versos 
positivamente intercalados à última hora o atestam - e se reservasse para cantar a vitória sobre o Miramolim, com que D. Sebastião andava a sonhar desde que lhe fizeram a entrega do Reino".

b) E defendida também por Hermano Saraiva - Vida ignorada de Camóes ( $1^{\text {a }}$ ed. 1978), às páginas 383-384 da 2a edição de 1980 - ao propor que, além das estâncias 83-86 do Canto VII, das estrofes 26-28 e 93-95 do Canto IX, referidos pela peça do Sr. Saramago, Camôes teria inserido ainda as estâncias 54-55 do Canto VIII. A suposição baseia-se na semelhança entre as estrofes e as críticas que circulavam anonimamente em pasquins à época em que o poeta se encontrava em Lisboa:

"Isso leva a concluir que as estâncias que visam os Câmaras (VII, 84-85) e censuram o rei (VIII, 54-55, IX, 26-28) traduzem uma opiniấo que Camóes conheceu em Lisboa precisamente pela altura em que o poema foi editado. É possível que se trate de estrofes intercaladas já na fase dos prelos, porque elas estão em contradição com o encarecimento incondicional traduzido noutras estrofes, designadamente no canto I", pois "a coincidência entre a matéria dos panfletos e a de Os Lusíadas é táo flagrante que náo pode ser casual. Camóes foi um dos porta-vozes do descontentamento dos nobres contra o valido do rei".

V. Tampouco é inédita a releitura do Sr. José Saramago no capítulo referente às emendas que o poema teria sofrido à mão do censor, Frei Bartolomeu Ferreira.

Uma leitura atenta do segundo ato, quadros 2 e 4, a tratar das emendas sugeridas e/ou impostas ao poema pela censura inquisitorial, talvez náo se equivocasse ao dizer que o Sr. José Saramago teve por modelo dois conhecidos textos de Aquilino Ribeiro, a saber: Camóes, Camilo, Eça e alguns mais (cuja primeira edição data de 1949) e Luís de Camóes. Fabuloso. Verdadeiro ( primeira edição de 1950).

Os reparos que o censor faz a passagens de Os Lusiadas, na peça, são coincidentemente os mesmos encontrados nas páginas dos referidos livros de Aquilino Ribeiro. Vejamos, à guisa de ilustração, apenas algumas coincidências mais evidentes:

1. - Na peça (II, 2 - p. 119), reparo do censor às estâncias 70-91 do canto VI (a tempestade que se abate sobre a frota já próxima da Índia), defendendo-se Camóes com a lembrança das estâncias 93-94 do mesmo canto (agradecimento de Vasco da Gama a Deus):

"Frei Bartolomeu Ferreira: - Posto que de ambas as vezes me chocou aquele passo em que Vasco da Gama invoca a Divina Guarda para que o proteja e defenda no transe aflito em que está, e quem o ouve e lhe acode é Vénus. Dizei-me logo. Por que não fizestes vós intervir a Virgem, ainda por cima Domina Maris, Senhora do Mar? O trágico passo haveria de ter assim uma unção religiosa, um fervor, que dessa maneira lhe faltam, tudo se resolvendo entre ninfas que vão a seduzir os ventos, e assim acaba a tempestade. Que me dizeis a isto?

Camóes: - (...) Vindo eu a escrever de falsas religióes e falsos deuses, como poderia, sem cair em grave escândalo, e talvez pecado, chamar a terreiro a 
verdadeira fé? Basta que terminada a tempestade agradeça Vasco da Gama. E a quem agradece? Ao único e verdadeiro deus.”

Em Luis de Camóes. Fabuloso. Verdadeiro, pp. 138-139 do vol II, a propósito do "hibridismo mitológico de que padecem os Lusíadas, e de que pela certa Fr. Bartolomeu é responsável” (p. 135), lê-se a seguinte referência ao episódio da tormenta:

"Na descrição da tormenta, estupenda de realidade, bate tonitruante a cólera dos deuses, movidos por Baco, mas não tarda o antídoto da intervenção cristá... Vasco da Gama invoca a misericórdia da

Divina Guarda, angélica, celeste,

Que o céu, o mar e terra senhoreias... (VI, 80)

E como num tecido de mescla, com o fio de estopa cristão entrança-se o fio de ouro e cetim de Vénus, mandando as ninfas aplacar Bóreas e os furiosos deuses da tempestade, ao passo que brada o piloto de Melinde:

- Terra é de Calecut, se não me engano! (VI, 92)

O almirante cai de joelhos e dá graças, é claro que ao seu Deus.” (VI, 93)

2. - Na peça (II, 2, p. 120) defende Camões a intervenção do maravilhoso pagão

"Já pensou Vossa Reverença como seria o meu livro se em vez dos deuses e das musas dos antigos romanos, as intervençôes do divino estivessem a cargo da Virgem, de Nosso Senhor Jesus Cristo e dos santos?”

Como se estivesse a responder a reprovação do censor inscrita nas páginas 129-130 de Camóes. Fabuloso. Verdadeiro:

"Mas já lhe digo, gostaria que desse menos relevo ao papel que faz representar aos deuses pagáos. (...) Bem sei que me vem argumentar com o pitoresco... o velho guarda-roupa das musas... e a reserva respeitosa que exigem o Deus Todo-Poderoso e mais pessoas consagradas pela teodicéia."

3. - O diálogo da peça do Sr. José Saramago com a fabulação e idéias do Sr. Aquilino Ribeiro prossegue, quando, ainda nesse segundo quadro do segundo ato (p. 121), Frei Bartolomeu verbaliza numa pergunta a Camóes

“(Agora que sobre isto me fizeste pensar, outra pergunta ainda vos faço: por que não vos haveis servido de Satanás para inimigo dos portugueses e das suas obras? Mostraríeis, assim, uma vez mais, o triunfo da fé sobre as malícias do inimigo.)"

o discurso indireto-livre de seu pensamento em Camóes, Camilo, Eça e alguns mais, p.23:

"A efabulação do poema cinca pela representação que nela têm os deuses do paganismo. A que vem Baco, quando a santa teologia tem melhor, 
incomparavelmente melhor, em Satanás e nas suas múltiplas prefiguraçôes, Belzebut, Asmodeu, Lusbel, etc., etc.?”

4. - Outro reparo do censor na peça, à página 122, atinge em cheio a Ilha dos Amores (IX, 52-92) - matéria, por sinal, do opúsculo Camóes e o Frade na Ilha dos Amores, que, saído em 1946, serviu de base para os volumes já aqui citados em que Aquilino Ribeiro defende a tese de que o Frei Bartolomeu Ferreira deixou passar a ilha dos Amores, "em troca da enxertia no poema das sete últimas estâncias do canto IX (88-95), o sermáo do apostolado; das estâncias 82,83,84 (do Canto X) ou a retractação; e das estâncias 108 à 119 (no Canto X) ou a lenda de S. Tomé.» (Camóes, Camilo, Eça $e$ alguns mais, p. 29).

A peça do Sr. José Saramago, nesse capítulo aquiliniano de enxertias, alude, no final do segundo quadro do segundo ato, à retratação, ou seja, à intromissão censória na estância 82 do canto X:

"Por hoje temos conversado. Ainda haveremos de examinar certos outros pontos, tenho algumas propostas de correcção a fazer-vos, é do vosso interesse que concordeis com elas. Conviria, dou-vos só este exemplo, que dissésseis, logo veremos em que passo do poema, que os deuses servem apenas para inspirar versos, e nada mais."

VI. Assim viu o Sr. José Saramago os acrescentamentos e emendas que Os Lusíadas teriam sofrido em Lisboa, às vésperas de sua publicação.

No que tange aos acrescentamentos inseridos já em Lisboa, sua versão coincide com as de Hermano Saraiva e Aquilino Ribeiro.

Quanto às emendas e correçôes impostas pela censura inquisitorial, sua óptica subscreve lição corrente entre os camonólogos (Gomes Amorim, D. Francisco Alexandre Lobo, Sebastiāo Mendo Trigoso, Francisco Evaristo Leoni, Pe. José Maria Rodrigues, Bowra), seguindo particularmente, e muito de perto, idéias e sugestôes do Sr. Aquilino Ribeiro.

Conclusão: Que farei com este livro?, a tratar da composição e publicação de Os Lusíadas, revela-se, não obstante tácito, um diálogo intertextual - parafrásico - com alguns títulos da bibliografia histórica e crítico-ensaística dedicada a Camóes, notadamente, Camóes, Camilo, Eça e alguns mais e o segundo volume de Luis de Camóes. Fabuloso. Verdadeiro."

Aí ficam a visão do leitor inexperto e o enfoque aquilino do leitor experto. Julgue cada um, à luz do visto, se destro foi o olho direito na leitura de Que farei com este livro? ou se foi o esquerdo quem destramente leu direito. 